\title{
SELECTION OF HEAT ACCUMULATING MATERIALS FOR SEASONAL SOLAR HEATING SYSTEMS
}

\section{Moskvitina Anna ${ }^{1}$}

DOI: https://doi.org/10.30525/978-9934-571-89-3_118

The necessity of heat accumulating in solar heating is associated with nonuniform daily and annual incoming and consumption of solar radiation. During the heating season incoming of solar radiation is minimal but heat consumption is maximal. So there is a good reason to consider the possibility to accumulate heat energy in summer with further using it for heating needs during mid-season and heating season.

Store of heat energy in accumulator could be calculated for several months or throughout the year. Relatively speaking using of interseasonal heat accumulator could improve energy efficiency level of heat supply from solar heating systems, as well as systems that use secondary energy resources and summer waste heat from cogeneration units.

Analysis of literary sources has shown that northlands pay much attention to the issue of seasonal heat accumulating. Most common in the world practice (they are very popular in Switzerland, Sweden, Denmark and Israel) are heat capacitative seasonal accumulators [1, p. 57; 2, p. 83] that used for residential buildings and cottage settlements. There are several constructional decisions of such seasonal accumulators.

In spite of the versatility in structure shapes of solar heat seasonal accumulators, their economic viability is low because of high capital investments. Cost-effective installation of seasonal accumulators requires payback period within the scope of $6 \ldots 8$ years. So today designing of effective seasonal accumulator is the main component of further development in heating from renewable and secondary energy sources.

Heat accumulating system generally includes heat-insulated storage reservoir with heat-accumulating material (accumulates and keeps heat energy) and heat-exchange equipment (supplies/carries away heat from heat-accumulating material by charging/discharging of heat accumulator).

Optimal energy efficiency level of heat accumulating and entire solar heating system depends on:

- capital cost of accumulator including construction cost of reservoir and value of heat-accumulating material (HAM);

- operation temperatures of HAM;

- operating costs of accumulator;

- capital costs and operational characteristics of solar collectors and other alternative sources of heat energy.

So the issue of choosing effective HAM (taking into account cost of HAM, its thermotechnical characteristics and construction cost of reservoir) is very important

\footnotetext{
${ }^{1}$ Kiev National University of Construction and Architecture, Ukraine
} 
at this time. We can find comparing of different heat-accumulating materials in the proceedings of Backman, Daffi and others [1, p. 102; 2, p. 138]. The analysis of literature sources has shown that when reasoned the choice of HAM, capital cost for building of seasonal accumulator were ignored.

In the process of seasonal accumulator designing must be taking into account the factors that have influence on specific value of heat-accumulation such as: specific heat capacity of HAM, its mass density and value, technologically feasible temperature range, environmental friendliness, resource availability and guaranteed service life [3, p. 241; 4, p. 138].

Analysis of influence mentioned above factors on value of accumulated heat allows propose the factorial criteria of optimization. On the ground of this criteria it's possible to compare different types of heat-accumulating materials:

$$
K_{o}=\frac{B}{c \cdot \rho \cdot\left(t_{c}-t_{d}\right)}, U A H / k J
$$

where, $c$ - specific heat capacity of $\mathrm{HAM}, \mathrm{kJ} / \mathrm{kg} \cdot{ }^{\circ} \mathrm{C} ; \rho$ - mass density of HAM, $\mathrm{kg} / \mathrm{m}^{3} ; c \cdot \rho$ - volumetric heat capacity of $\mathrm{HAM}, \mathrm{kJ} / \mathrm{m}^{3} \cdot{ }^{\circ} \mathrm{C} ; t_{c}$ - temperature of heataccumulator charging (depends on physical characteristics of HAM), ${ }^{\circ} \mathrm{C} ; t_{d}-$ temperature of heat-accumulator discharging (assume $55^{\circ} \mathrm{C}$ for heating, $45^{\circ} \mathrm{C}$ for domestic hot water system and $8^{\circ} \mathrm{C}$ for using heat pumps); 6 - specific cost of $1 \mathrm{~m}^{3}$ of heat-accumulator, determined from the formula:

$$
\text { в }=B_{t} / V, U A H / m^{3} ;
$$

where, $B_{t}$ - total value of heat-accumulator including value of HAM, materials for construction of reservoir and building works, UAH;

$\mathrm{V}$ - design volume of heat-accumulator, determined from the formula:

$$
V=\frac{Q \cdot 10^{6}}{c \cdot \rho \cdot\left(t_{c}-t_{d}\right)}, m^{3}
$$

where, Q - amount of heat energy that must be accumulated, GJ.

Technical and economic principle of the proposed optimization criteria $\left(K_{o}\right)$ is evaluation of specific costs for keeping (accumulating) of heat energy

To evaluate the different types of HAMs, let's consider the variant of using solar interseasonal heating for the typical cottage house with total area $S=250 \mathrm{~m}^{2}$ and specific heat losses for heating needs $E_{b}=400 \mathrm{MJ} / \mathrm{m}^{2}$ per annum. This indicator corresponds to the requirements of existing building codes.

$E_{b}=400 \mathrm{MJ} / \mathrm{m}^{2}$ per annum $=111 \mathrm{kWh} / \mathrm{m}^{2}$ per annum.

So the required amount of heat for heating needs is following:

$W=\mathrm{E}_{\mathrm{b}} \cdot \mathrm{S}=400 \mathrm{MJ} / \mathrm{m}^{2} \cdot 250 \mathrm{~m}^{2}=100000 \mathrm{MJ}$ per annum $=100 \mathrm{GJ}$ per annum.

Let's make a calculation for heat-accumulator with capacity $W=100 \mathrm{GJ}$ that could be installed under the building or near it. In case of under-building installation the walls of heat-accumulator could be used also as building footing. This would positively effect on the overall cost of the building.

Assumed construction of heat-accumulator is following: 
- hydraulic concrete with thickness $30 \mathrm{~mm}$;

- water-resistant heavy reinforced concrete with thickness $200 \mathrm{~mm}$;

- external heat insulation: mineral wool for walls of heat-accumulator and glass foam for bottom part of heat-accumulator with thickness $600 \mathrm{~mm}$;

- hydrofuge insulation (rubberoid).

Let's consider most common materials with high volumetric heat capacity (water, granite macadam, cast iron, concrete, mineral oil, goudron, glycerin) and prepare a technoeconomic study of using them as heat-accumulating materials for interseasonal solar heating system.

There are good reasons to use desalinized treated water from reverse osmosis system as heat-carrier. For comparing calculations for simple water and water with parameters $\mathrm{P}=1.5 \mathrm{~atm}$. and boiling temperature $105^{\circ} \mathrm{C}$ are shown below. The results of comparing HAMs are presented in Table 1.

Table 1

Comparing of heat-accumulating materials

\begin{tabular}{|l|c|c|c|c|c|c|c|c|}
\hline \multicolumn{1}{|c|}{$\mathrm{HAM}$} & $\begin{array}{c}\mathrm{c}, \\
\mathrm{kJ} / \mathrm{kg} \cdot{ }^{\circ} \mathrm{C}\end{array}$ & $\begin{array}{c}\rho, \\
\mathrm{kg} / \mathrm{m}^{3}\end{array}$ & $\begin{array}{c}\mathrm{c}^{*} \rho, \\
\mathrm{kJ} / \mathrm{m}^{3} \cdot{ }^{\circ} \mathrm{C}\end{array}$ & $\mathrm{t}_{\mathrm{c}},{ }^{\circ} \mathrm{C}$ & $\mathrm{t}_{\mathrm{d}},{ }^{\circ} \mathrm{C}$ & $\mathrm{V}, \mathrm{m}^{3}$ & $\begin{array}{c}\mathrm{B}_{\mathrm{t}}, \\
\text { th } \mathrm{UAH}\end{array}$ & $\begin{array}{c}\mathrm{K}_{\circ}, \\
\mathrm{UAH} / \mathrm{kJ} \cdot 10^{3}\end{array}$ \\
\hline Water & 4,187 & 975 & 4082,3 & 95 & 55 & 612 & 851 & 8,51 \\
\hline Water* & 4,187 & 925 & 3873,0 & 105 & 55 & 516 & 733 & 7,33 \\
\hline Cast iron & 0,482 & 7200 & 3470,4 & 140 & 55 & 339 & 52749 & 527,50 \\
\hline Concrete & 1,13 & 2242 & 2533,5 & 140 & 55 & 464 & 664 & 6,64 \\
\hline $\begin{array}{l}\text { Mineral } \\
\text { oil }\end{array}$ & 1,8 & 900 & 1620,0 & 140 & 55 & 726 & 18635 & 186,35 \\
\hline $\begin{array}{l}\text { Granite } \\
\text { macadam }\end{array}$ & 0,84 & 1600 & 1344,0 & 140 & 55 & 875 & 776 & 7,76 \\
\hline Glycerin & 2,43 & 1260 & 3061,8 & 140 & 55 & 384 & 6593 & 65,93 \\
\hline Goudron & 2,09 & 1000 & 2090,0 & 140 & 55 & 563 & 3436 & 34,36 \\
\hline
\end{tabular}

* Water with pressure of $1.5 \mathrm{~atm}$. and the boiling temperature $105^{\circ} \mathrm{C}$

The analysis of heat-accumulating materials has shown that granite macadam and concrete are the best suited for utilization of high-temperature heat from renewable energy sources (including solar heating systems) and excess high-temperature heat from cogeneration units and thermal power plants. Most expensive heat-accumulating material is cast iron. So using all potential of its operating temperature range (up to $800^{\circ} \mathrm{C}$ ) is essential. When we use nighttime tariffs for electricity it is possible to heat cast iron accumulator to $500-600^{\circ} \mathrm{C}$ and decrease the sizes of accumulator in 5-6 times. Water is the best suited for utilization of low-temperature heat (renewable and excess heat with temperature up to $95^{\circ} \mathrm{C}$ ). Expenditures for temperature increase of water are not justified because of complicating of system operation and costs for additional equipment. For heat-carrier with temperature higher $120^{\circ} \mathrm{C}$ it is wise to use granite macadam and concrete as heat-accumulating material. 


\section{References:}

1. Beckman NG, Gilli P. (1987). Thermal energy storage. Moscow: World.

2. Duffy J.A., Beckman W.A. (1977). Thermal processes using solar energy. Moscow: World. 3. Anderson B. Solar Energy (1982). Fundamentals of building design. Moscow: Stroiizdat. 